\title{
Effect of Heat Treatment on the Fatigue Life of Steel-Titanium Bimetal
}

\author{
Andrzej Kurek ${ }^{1, *}$ \\ ${ }^{1}$ Opole University of Technology, Mechanical Engineering Faculty, 5 Mikolajczyka Str., Opole, Poland
}

\begin{abstract}
The work presents results of explosively welded steel-titanium bimetal fatigue tests, as well as the native and clad-on materials. The tests were applied to specimens made of bimetal constituting fusion of S355J2 steel with SB 265 G1 titanium, where the latter was the material being clad-on during plating process. Both the material prior to plating (the titanium) and following plating was tested, as well as prior to and following the heat treatment process. The tests result in fatigue life of specimens made of native material, acquired from the plater, being lower than that of the steel-titanium bimetal specimens fatigue life, while the fatigue life of SB 265 G1 titanium does not change significantly in result of plating. Furthermore, the state of stress in the plater native layer following welding (compressive stress), positively influences its fatigue life, this effect being insignificantly reduced by heat treatment.
\end{abstract}

\section{Introduction}

Technology of explosive welding enables permanent fusion of materials that have very different properties, difficult to achieve with another welding techniques [1]. The claddings obtained with this method are materials exhibiting highly gradient properties and have complex nature of fusion zone. One of the clad materials key utilisation areas are process equipment constructions (power engineering and chemical industries). Wide use of titanium and its alloys in power engineering (condensers, steam condensers, heat exchangers and steam turbines in power plants and combined heat and power plants) makes the problem of the steel-titanium bimetals fatigue life more and more important. Both in these and other applications, the fatigue life of the clads is the key parameter. In a view of the problem specifics, both tests specified by adequate standards and nonstandardized tests are performed. The strength tests presented in the work relate to metallic composite, called cladding, obtained in process of so-called explosive cladding. The problem of residual stress in explosively cladded materials is extensively shown in papers [2,3], The aim of the work is comparing results of fatigue tests on specimens made of native materials (steel and titanium) and the bimetal in two states, prior to, and after heat treatment, followed by determining its impact on fatigue life of resulting product.

\section{Materials and methods}

The work presents results of fatigue testing material, being a fusion of S455J2 steel with SB265 G1 titanium as the material being clad on, as well as steel being the native material and titanium SB265G1. Considering thickness of the layer being clad on - titanium $(6 \mathrm{~mm})$, specimens having non-standardized dimensions and shape have been used in fatigue testing. Prior to commencing the test, the shape of specimens should have been determined, which was accomplished with use of FEM calculations aimed at determining a size and shape of the specimen, ensuring sufficient stress level in the materials.

The specimens of elaborated shape $(100 \times 9 \times 9 \mathrm{~mm})$ were used for fatigue tests, that were performed on the MZGS-100 fatigue test stand, constituting an equipment of fatigue testing laboratory in Department of Mechanics and Machine Design of Opole University of Technology [4] (Fig. 1), the test were conducted under controlled bending momentum with constant frequency $(30 \mathrm{~Hz})$.

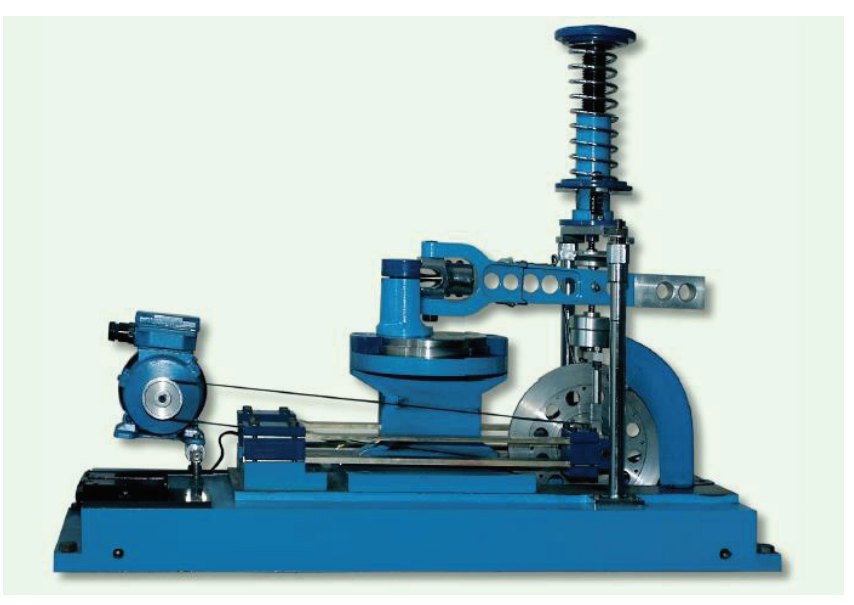

Fig. 1. MZGS-100 fatigue test stand

The specimens made of clad material have been produced such that bimetal joint would run precisely in

Corresponding author: a.kurek@po.opole.pl 
the middle of their cross-section, dividing the specimen into two equal halves - the steel one and the titanium one (Fig. 2).

In the first series of tests the specimen was fastened in the machine so that bending would be performed according to the scheme (Fig. 3a), in the plane perpendicular to the bimetal joint. For test of such type, initial fatigue tests were done that have been presented in the works $[5,6]$. The results of this research are shown in Table 1a and Figs. 4-6. They have been depicted as specimens loaded perpendicularly to the bimetal joint plane. The subsequent series was performed with another clad loading configuration, the specimen was fastened in the fatigue tester so that moment vector would act within bimetal joint plane (Fig. 3b). The results of tests that have been presented in the works [5,6], are compiled in Table $1 \mathrm{~b}$ and Figs. 5, 6 and depicted as specimens loaded parallel to the bimetal joint plane.

The third series of tests has been done on specimens prepared from native material (the $\mathrm{S} 355 \mathrm{~J} 2$ steel) that were acquired from plates previously explosively welded. In order to create possibility of correlating obtained test results with the two previous test series, the specimens of the same shape and dimensions as used for the first and the second test series have been employed. Results of those test that were presented in the works $[5,6]$, have been placed in Table $3 \mathrm{~b}$ and in Fig. 6 .

The subsequent series of tests was performed on specimens made of native material, SB265G1 titanium, in condition as prior to cladding. The results of tests performed with specimens, having the same shape and dimensions as in previous series of tests, are listed in Table $3 \mathrm{a}$ and in Figs. 4-6.

The last series of tests related to clad material, sampled from the same test plate, but prior to subjecting it to heat treatment. The specimens for testing were prepared similarly, as in case of the first and the second series of tests. The results are shown in Table 2 and Fig. 7.

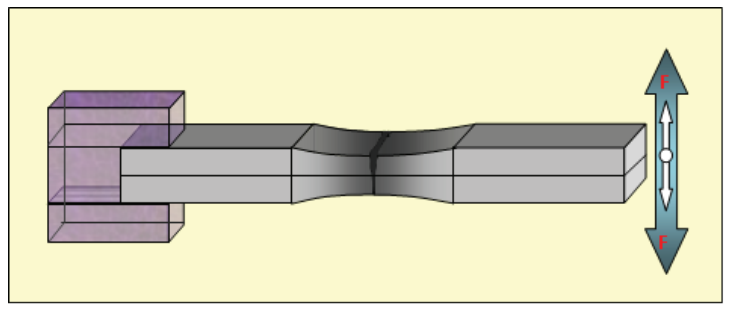

Fig. 2. Schematic of specimens fastening and loading [7].

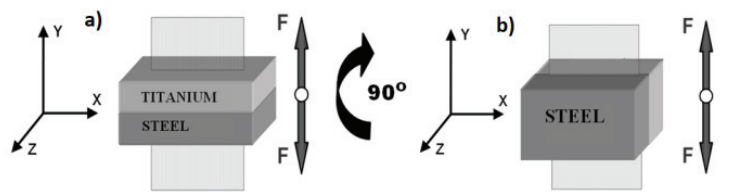

Fig. 3. Schematics of loading manner dependent on specimen fastening: "perpendicular" (a) and "parallel" (b) [7].

Considering that MZGS-100 fatigue test stand enables execution of tests at constant bending moment value, the stress magnitude values shown in the tables have been determined by means of FEM calculations, assuming the linear-elastic material model.

Table 1. Test parameters and fatigue life of the steel-titanium bimetal, for loading bimetal perpendicularly a) and parallel b) to the joint plane, the material after heat treatment $(\mathrm{HT})$.

\section{a) Perpendicularly}

\begin{tabular}{|c|c|c|c|}
\hline no. & $\begin{array}{c}\boldsymbol{\sigma}_{\mathbf{a}}, \mathbf{M P a} \\
\text { steel }\end{array}$ & $\begin{array}{c}\boldsymbol{\sigma}_{\mathbf{a}}, \mathbf{M P a} \\
\text { titanium }\end{array}$ & $\mathbf{N}_{\mathbf{f}}$ \\
\hline 1 & 380 & 266 & 56000 \\
\hline 2 & 367 & 257 & 77000 \\
\hline 3 & 360 & 252 & 133000 \\
\hline 4 & 347 & 243 & 95000 \\
\hline 5 & 343 & 240 & 101000 \\
\hline 6 & 328 & 230 & 156000 \\
\hline 7 & 321 & 225 & 238000 \\
\hline 8 & 294 & 206 & 345000 \\
\hline 9 & 274 & 192 & 1760000 \\
\hline 10 & 287 & 201 & 172000 \\
\hline
\end{tabular}

\section{b) Parallel}

\begin{tabular}{|c|c|c|c|}
\hline no. & $\begin{array}{c}\boldsymbol{\sigma}_{\mathbf{a}}, \mathbf{M P a} \\
\text { steel }\end{array}$ & $\begin{array}{c}\boldsymbol{\sigma}_{\mathbf{a}}, \mathbf{M P a} \\
\text { titanium }\end{array}$ & $\mathbf{N}_{\mathbf{f}}$ \\
\hline 1 & 371 & 185 & 132000 \\
\hline 2 & 361 & 180 & 79000 \\
\hline 3 & 351 & 175 & 98000 \\
\hline 4 & 339 & 169 & 235000 \\
\hline 5 & 336 & 168 & 143000 \\
\hline 6 & 316 & 157 & 241000 \\
\hline 7 & 280 & 140 & 368000 \\
\hline 8 & 278 & 139 & 453000 \\
\hline 9 & 260 & 130 & 5039000 \\
\hline 10 & 259 & 129 & 965000 \\
\hline
\end{tabular}

The fatigue test results for steel-titanium bimetal, and titanium in condition preceding the joining action, depending on $\sigma_{\mathrm{a}}$ stress magnitude and $\mathrm{N}_{\mathrm{f}}$ number of cycles, are shown in Fig. 4. In case of the steel-titanium bimetal, the diagram presents results obtained for the specimen loading case in the plane perpendicular to the bimetal joint (Fig. 3a), with consideration given to stress amplitude, applied in the test conditions, present in SB265 G1 titanium. On the grounds of tests, distinguish differences between fatigue lives obtained from material tests prior to and following the fusion action, has not been found, therefore a common fatigue characteristics is applied. The Basquin stress-life curve was used and the equation is presented on figures. 
Table 2. Test parameters and fatigue life of the steel-titanium bimetal, for loading bimetal perpendicularly to the joint plane, the material prior to heat treatment (HT).

\begin{tabular}{|c|c|c|l|}
\hline no. & $\begin{array}{c}\boldsymbol{\sigma}_{\mathbf{a}}, \mathbf{M P a} \\
\text { steel }\end{array}$ & $\begin{array}{c}\boldsymbol{\sigma}_{\mathbf{a}}, \mathbf{M P a} \\
\text { titanium }\end{array}$ & \multicolumn{1}{|c|}{$\mathbf{N}_{\mathbf{f}}$} \\
\hline 1 & 385 & 270 & 355000 \\
\hline 2 & 407 & 285 & 129900 \\
\hline 3 & 355 & 249 & 680980 \\
\hline 4 & 351 & 246 & 423776 \\
\hline 5 & 332 & 233 & 793401 \\
\hline 6 & 321 & 225 & 1281800 \\
\hline 7 & 396 & 278 & 184800 \\
\hline 8 & 409 & 287 & 80095 \\
\hline 9 & 317 & 222 & 4000000 \\
\hline 10 & 385 & 270 & 400006 \\
\hline 11 & 364 & 255 & 270000 \\
\hline 12 & 372 & 261 & 276674 \\
\hline 13 & 430 & 302 & 95250 \\
\hline 14 & 387 & 272 & 289900 \\
\hline 15 & 428 & 300 & 119000 \\
\hline 16 & 377 & 264 & 284500 \\
\hline 17 & 332 & 233 & 2500000 \\
\hline
\end{tabular}

Table 3. Test parameters and fatigue life of SB265 G1 titanium (a) and native material, S355J2 steel (b).

a) SB265G1 titanium

\begin{tabular}{|c|c|l|}
\hline no. & $\boldsymbol{\sigma}_{\mathbf{a}}, \mathbf{M P a}$ & \multicolumn{1}{|c|}{$\mathbf{N}_{\mathbf{f}}$} \\
\hline I & 311 & 8900 \\
\hline II & 306 & 14900 \\
\hline III & 283 & 38100 \\
\hline IV & 262 & 27800 \\
\hline V & 245 & 52100 \\
\hline VI & 235 & 119400 \\
\hline VII & 230 & 491300 \\
\hline VIII & 228 & 241800 \\
\hline IX & 214 & 1227800 \\
\hline$X$ & 201 & 327800 \\
\hline XI & 196 & 2262400 \\
\hline XII & 195 & 3708800 \\
\hline
\end{tabular}

b) $\mathrm{S355J2}$ steel

\begin{tabular}{|c|c|c|}
\hline no. & $\begin{array}{c}\boldsymbol{\sigma}_{\mathbf{a}}, \mathbf{M P a} \\
\text { steel }\end{array}$ & $\mathbf{N}_{\mathbf{f}}$ \\
\hline I & 329 & 78000 \\
\hline II & 314 & 84000 \\
\hline III & 303 & 156000 \\
\hline IV & 291 & 175000 \\
\hline V & 272 & 165000 \\
\hline VI & 271 & 195000 \\
\hline VII & 253 & 612000 \\
\hline
\end{tabular}

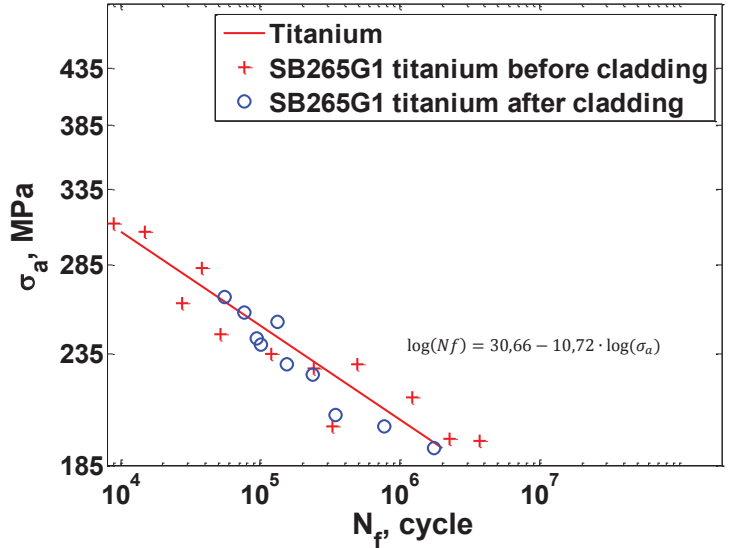

Fig. 4. Diagram of stress amplitude dependence $\sigma_{\mathrm{a}}=\mathrm{f}\left(\mathrm{N}_{\mathrm{f}}\right)$, present in titanium.

In Fig. 5 the fatigue test results are shown for steeltitanium bimetal, presenting $\sigma_{\mathrm{a}}$ stress amplitude (in steel and titanium) dependence on $\mathrm{N}_{\mathrm{f}}$ fatigue life for two manners of clad material loading and for native material, SB265 G1 titanium, together with characteristics considering stress amplitude applied in test conditions, present both in S355J2 steel and SB265 G1 titanium. On the grounds of tests, distinguish differences between fatigue lives obtained from the steel-titanium clad tests depending on loading type, has not been found, therefore a common fatigue characteristics is applied.

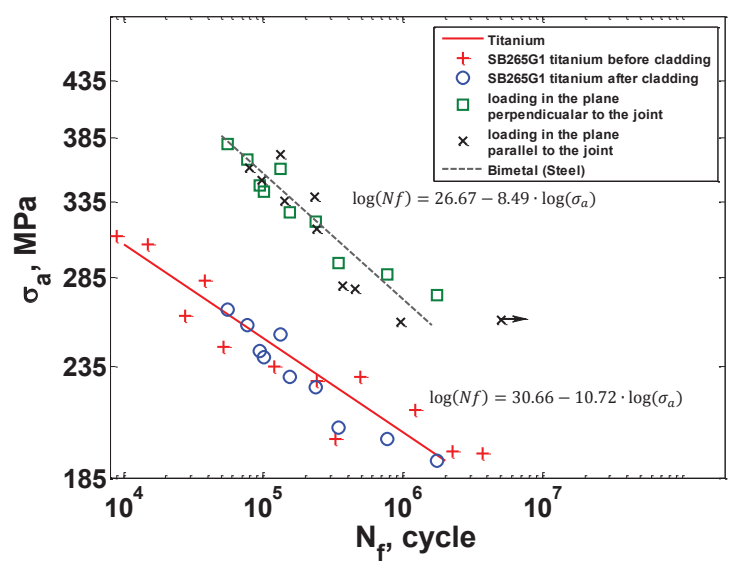

Fig. 5. Diagram of stress amplitude dependence $\sigma_{\mathrm{a}}=\mathrm{f}\left(\mathrm{N}_{\mathrm{f}}\right)$, present in steel and titanium.

The dual-log diagram (Fig. 6) presents results of fatigue tests showing stress amplitude $\sigma_{a}$ (in steel) dependence on $\mathrm{N}_{\mathrm{f}}$ fatigue life, for two types of clad material loading (presented by means of common characteristics), and for native material (S355J2 steel) and native material (SB265 G1 titanium).

The dual-log diagram (Fig. 7) presents collectively results of all fatigue tests as a stress amplitude $\sigma_{a}$ (in steel) dependence on $\mathrm{N}_{\mathrm{f}}$ fatigue life, those results are contained in Tables 1-3. 


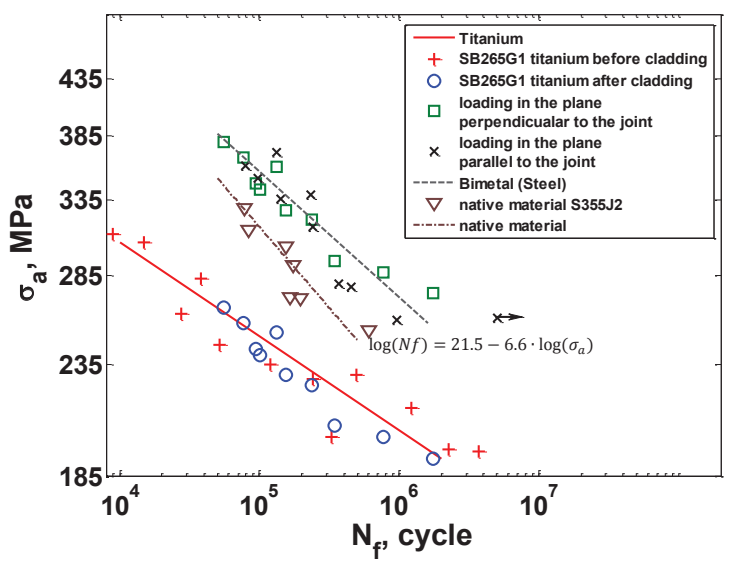

Fig. 6. Diagram of stress amplitude dependence $\sigma_{\mathrm{a}}=\mathrm{f}\left(\mathrm{N}_{\mathrm{f}}\right)$, present in steel, titanium and clad material.

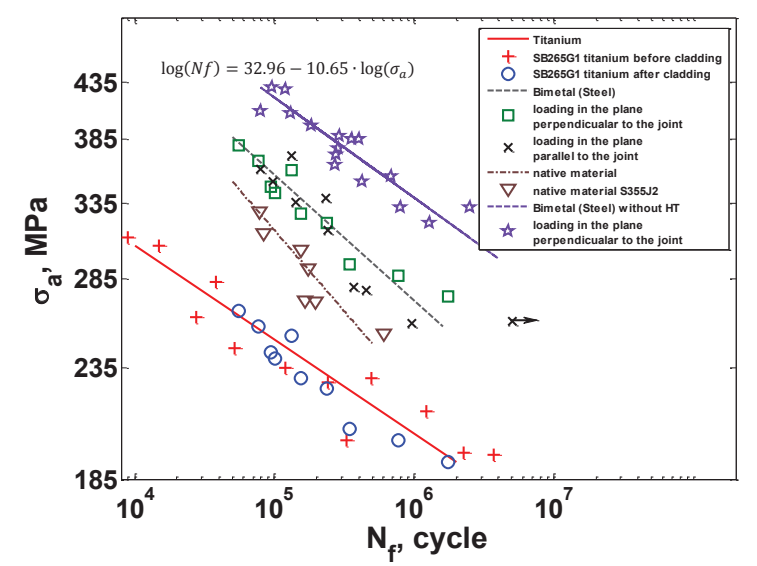

Fig. 7. Collective diagram of stress amplitude dependence $\sigma_{\mathrm{a}}=\mathrm{f}\left(\mathrm{N}_{\mathrm{f}}\right)$.

It should be noted, however, that indispensable part of fatigue test are scatters of experimental results, which are also present for uniform materials, and in case of bimetallic materials, clad with explosive method, we are facing non-uniform material structure, which may strengthen differences in test results for similar loads.

\section{Conclusions}

For the majority of tested, heat treated bimetal specimens, loaded perpendicularly to the joint plane, it was the SB265 G1 titanium material in which fracturing was initiated, which despite high difference of joined materials Young moduli, determining lower stress value, was characterised with lower fatigue life. The obtained in such manner values of the clad fatigue life, with consideration given to stress amplitudes within titanium layer, are comparable to SB265 G1 titanium fatigue lives in basic condition, preceding the explosive cladding stage. This enables to claim, with high likelihood, that it is possible to use fatigue characteristics determined for the material in basic condition, when evaluating fatigue life for elements made of clads containing this material. In case of specimens being bent in plane parallel to the plane of joint, fracture initiation occurs in the steel layer of the bimetal. This results from the higher difference of stress amplitudes present in steel and in titanium in such case, which entails fracture initiation process occurring earlier in the steel part of the bimetal. However, the fatigue life of such bimetal is markedly higher than fatigue life of native material.

It comes from the tests, that fatigue life of specimens made of native material, acquired from the clad, is lower than that of titanium-steel specimens.

Furthermore, the test results enable to claim that heat treatment used by manufacturer negatively influences fatigue life of the bimetal. Such condition may be explained by removing internal stresses from material or by introduction of new, lower compressive stresses, considering difference in thermal expansion parameters of joined materials. This hypothesis however requires additional research.

\section{References}

1. M. Gloc, M. Wachowski, T. Płocinski, K. J. Kurzydlowski, J. Alloys Compd. 671, 446-451, (2016)

2. A. Karolczuk, M. Kowalski, Key Eng. Mater. 592593, 594-597 (2014)

3. A. Karolczuk, M. Kowalski, G. Robak, Solid State Phenom. 199, 460-465 (2013)

4. A. Kowalski, W. Ozgowicz, M. Kurek, A. Kurek, T. Łagoda, Fratt. Integr. Strutt. 35, 449-455 (2016)

5. A. Kurek, M. Wachowski, A. Niesłony, T. Płocinski, K.J. Kurzydłowski, Arch. Metall. Mater. 59, 4, 1565-1570, (2014)

6. A. Kurek, A. Niesłony, Mater. Sci. Forum. 726, 106-109, (2012)

7. A. Niesłony, A. Kurek, R. Bański, L. Cížek, Sci. Fasc. Opole Uni. Tech., Mech. 97, 337, 41-42, (2010)

8. A. Karolczuk, K. Kluger, M. Kowalski, F. Zok, G. Robak, Mater. Sci. Forum, 726, 125-132 (2012) 